\title{
Ankaferd blood stopper accelerates deep second degree burn wound healing in rats
}

\author{
Ayse Topal ${ }^{1}$, Nihal Y. Gul Satar ${ }^{1}$, I. Taci Cangul², M. Ayberk Oktay ${ }^{1}$, Kivanc Inan ${ }^{1}$, \\ Goksen Cecen ${ }^{1}$, E. Pinar Akarsu ${ }^{1}$, Hakcahan Can ${ }^{1}$ \\ Uludag University, Faculty of Veterinary Medicine, ${ }^{1}$ Department of Surgery, ${ }^{2}$ Department of Pathology, \\ Nilufer/Bursa, Turkey
}

Received June 13, 2017

Accepted June 27, 2018

\begin{abstract}
In this study, the effects of Ankaferd Blood Stopper (ABS) and silver sulphadiazine (SSD) cream on burn wound healing were investigated in rats. A total of 24 outbred, male, Sprague-Dawley rats were randomly allocated to (1) ABS, (2) SSD, and (3) control groups. Bilateral burn wounds were created near the caudal border of the scapula. Wounds in each group were treated daily with sponges soaked in ABS solution, 1\% SSD cream, or saline, respectively. On days 0, 7, 14, 21, and 28 , unhealed wound area was measured and biopsy samples were taken for histopathological examination (except day 0 ). At the end of day 28, all rats in the ABS and SSD groups had complete coverage of the wounds with granulation tissue and epithelialization, whereas wounds in the control group were not completely epithelialized. On day 7, the mean unhealed wound areas and the mean percentages of wound contraction were not significantly different among the groups. However, the mean percentage of wound contraction in the ABS and SSD groups was significantly higher than in the control group on days 14,21 , and 28 . Histopathologically, wound healing was characterized by a decrease in neutrophil counts and an increase in vessel counts. Our results suggest that ABS can be successfully used for burn wound healing besides SSD.
\end{abstract}

Epidermis and dermis, topical treatment, wound planimetry, histopathological evaluation

Burns are lesions of thermal origin due to exposure to flames, hot surfaces and liquids, extreme cold, chemicals, radiation, or friction (Tavares Pereira Ddos et al. 2012a). Burns are classified from the $1^{\text {st }}$ to the $4^{\text {th }}$ degree according to their depth and severity. Second degree burns are subdivided as superficial and deep, the former involving the epidermis and superficial dermis (Tavares Pereira Ddos et al. 2012b). Burn wound surfaces are sterile immediately following thermal injury. However, colonization with autogenous microorganisms or through contact with the contaminated environment generally occurs within $48 \mathrm{~h}$ (Elsner et al. 2011).

In the treatment of burns, the aim is to treat the wound area, prevent infections, and achieve the best functional and aesthetic results in a short period with low costs (Arslan et al. 2012). The ideal wound dressing, therefore, must have strong antibacterial properties, coupled with a weak, clinically negligible cytostatic effect on regenerating tissues (Juhász et al. 2012). Unfortunately, the management of burn wounds still remains a matter of debate and an ideal dressing for burn wounds has not been discovered (Gupta et al. 2011).

In the topical treatment of burn wounds, $1 \%$ silver sulphadiazine (SSD) cream is one of the most commonly used agents worldwide. The SSD has been shown to decrease bacterial contamination, to hasten epithelialization, and to delay wound contraction. However, in some studies SSD has been shown to delay wound healing and separation of scar tissue, to cause atrophic and hypertrophic scars, to have renal toxicity, to cause leukopaenia, and to carry a risk for resistance (Fuller 2009; Arslan et al. 2012).

Ankaferd Blood Stopper (ABS) is a standardized herbal extract obtained from five different plants (Thymus vulgaris, Glycyrrhiza glabra, Vitis vinifera, Alpinia officinarum,

Address for correspondence:

Dr. I. Taci Cangul

Uludag Universitesi

Veteriner Fakultesi

Patoloji Anabilim Dali

16059 Nilufer/Bursa, Turkey

Phone: +90 2242941304

E-mail: itcangul@uludag.edu.tr

http://actavet.vfu.cz/ 
and Urtica dioica). The extract has been approved for the clinical management of bleeding resulting from external trauma and dental surgery, and has been used to manage haemorrhage in difficult clinical conditions (Saribas et al. 2010). The agent also has antiinfective (Tavares Pereira Ddos et al. 2012b), wound healer (Akbal et al. 2012; Akalin et al. 2014), and antineoplastic properties (Saribas et al. 2010; Arslan et al. 2012), besides providing the restoration and maintenance of tissue homeostasis (Tavares Pereira Ddos et al. 2012a).

We hypothesized that ABS accelerates and/or improves repair of the epidermis and dermis in deep second-degree burn wounds and we designed an experimental study in rats to assess the effects of ABS on burn injuries by comparing it with SSD cream and control.

\section{Materials and Methods}

Study population

Upon approval of the Animal Ethics Committee, the study was performed at the Experimental Animal Breeding and Research Unit of the Uludag University, Bursa, Turkey.

A total of 24 outbred, male Sprague-Dawley rats (mean weight \pm SD: $220 \pm 24$ g; mean age: 3 months) were used. The animals were kept in individual cages in a room with constant temperature $\left(22 \pm 4{ }^{\circ} \mathrm{C}\right), 12 \mathrm{~h}$ light $/ 12 \mathrm{~h}$ dark cycle, and had free access to food and water. The rats were randomly divided into three groups: (1) ABS group, (2) SSD group, and (3) control group (only saline applied), each group with eight rats. Prior to anaesthesia, and on days 7,14 , and 21 , a complete blood cell count was performed on each rat. Lateral tail vein was used for obtaining $0.4 \mathrm{ml}$ of blood by a 21 gauge needle.

Creation of second degree burn wounds in rats

The rats were starved for $24 \mathrm{~h}$ preoperatively. On day 0 , rats in all groups were anaesthetized by inhalation chamber of sevoflurane $(4.0-5.0 \%$, vol/vol). After the induction, anaesthesia was maintained with facial mask by inhalation of sevoflurane $(2.5-3.5 \%$, vol/vol $)$. A single dose of enrofloxacin $\left(10 \mathrm{mg} / \mathrm{kg}\right.$, s.c., Baytril ${ }^{\circledR}$, Bayer, Leverkusen, Germany) was administered immediately preoperatively for prophylaxis. The hair on the dorsum was clipped widely from the scapula to the ilium region and the clipped area was surgically prepared with polyvidone-iodine (Betadine ${ }^{\circledR}$, Kansuk, Istanbul, Turkey). Each rat was positioned in sternal recumbency and surgically draped.

Burn wounds were created on the dorsal side of the rats using an instrument as described by Lakshmi et al. (2011) (Plate VI, Fig. 1). The soldering equipment was connected to a digital thermoregulator. The tip of the rod was soldered to a circular brass disc of a $2 \mathrm{~cm}$ diameter and achieved a partial thickness contact burn injury. The circular disc was heated to $88-90{ }^{\circ} \mathrm{C}$ and the temperature was allowed to stabilize for $20 \mathrm{~min}$, after which the external contacting surface of the circular brass disc was placed over the shaved dorsal side of rats for $20 \mathrm{~s}$ without exerting any external pressure. Burn wounds were created on each side, nearly $1 \mathrm{~cm}$ from the dorsal midline just caudal to the caudal border of the scapula on each rat. The extent of the burn was traced onto a transparent paper as a reference for later follow-up. Analgesia was maintained with carprofen $\left(4 \mathrm{mg} / \mathrm{kg}\right.$, s.c., Rimadyl ${ }^{\circledR}$, Pfizer Inc., Zaventem, Belgium) injected intramuscularly to all animals immediately after the procedure and once per day for three consecutive days. Figure $1 \mathrm{~b}$ shows the depth of the wound. The depth of the wounds was verified through histological examination of the skin biopsies taken in a pilot study prior to the main study (data not shown).

Burn wound treatment and clinical evaluation

After creating burn wounds, the rats were left undisturbed for $24 \mathrm{~h}$ and observed for any signs of discomfort such as decreased appetite or reluctance to move. Thereafter, the first group was administered ABS solution (Ankaferd Blood Stopper ${ }^{\circledR}$ sol., Ankaferd Drug Cosmetic Co., Istanbul, Turkey) by compressing ABS soaked sterile gauzes for five minutes. The second group was applied 1\% SSD cream (Silvezin ${ }^{\circledR}$, Deva Holding, Istanbul, Turkey). Enough medication to cover the wound with a thin layer was applied by delivering a segment of the medication diagonally across the circular wound. The third group was compressed with saline soaked sterile gauzes for five minutes. All applications were performed once a day and rats were treated until the wounds healed. The clinical course of skin lesions for blistering, swelling, colour change, crust, exudation, granulation tissue, and scar tissue was evaluated for 28 consecutive days.

\section{Planimetry}

Planimetry was performed on days $7,14,21$, and 28 on anaesthetized animals (anaesthesia protocol used to create burn wounds was repeated) by tracing the perimeter of the circular wounds onto a sterile piece of acetate film with a special marking pen. The examiner, wearing a $\times 2.5$ loupe, traced the wound margin at the border between the closed (epithelialized) and open (non-epithelialized, bleeding) wound areas. Wound contraction was expressed as reduction in the percentage of the original wound size. Wound tracings were scanned and transferred to a computer, and the area $\left(\mathrm{mm}^{2}\right)$ and perimeter were calculated for each wound tracing using the Sigma Scan ${ }^{\circledR}$ 
software (SPSS Inc., Chicago, IL, USA). The percentage of wound contraction for wounds on the right side was calculated by the following formula, as described by Kumar et al. (2006):

$\%$ wound contraction on day $\mathrm{X}=([$ area on day 0 - open area on day $\mathrm{X}] /$ area on day 0$) \times 100$

Histopathological examination

The circular wounds on the left side were divided into four virtual quarters and $4 \mathrm{~mm}$ punch biopsy instruments were used to take skin specimens from different quarters on days 7, 14, 21, and 28 immediately after the planimetry was performed. Skin specimens were fixed in $10 \%$ neutral buffered formalin and processed routinely for histopathological examination. Five-micrometre sections were stained with haematoxylin and eosin (H\&E). In every skin section, an area just beneath the burn area or crust formation was randomly selected. Thereafter, four consecutive areas moving towards the deep dermis were selected. The five selected areas were examined under $\times 400$ magnification. The neutrophil count was scored as $0-25=1,26-50=2,51-75=3$, and $>75=4$. The same areas were also examined for the number of vessels and the actual count was noted. All histological sections were blindly evaluated by the same investigator (ITC).

\section{Statistical analysis}

The percentage of total wound healing and unhealed wound area for each wound at each time of measurement as compared to the original wound size were calculated. The mean values were compared among the three groups using repeated measures model for analysis of variance (ANOVA). Where differences existed, the differences were determined by Duncan's multiple-range test. Neutrophil scores and vessel counts were analysed using oneway ANOVA. When differences among the groups were significant, Mann Whitney U test was used. All analyses were performed using SPSS 13.0 software (SPSS Inc.). A $P$ value $<0.05$ was considered significant.

\section{Results}

Complete blood cell count values were within normal limits for all samples taken on days $0,7,14$, and 21 (data not shown).

\section{Clinical evaluation}

The progress of wound healing in each group is shown in Figure 2. After creating deep second degree burns on the dorsum of the rats, the burn area was tan red coloured in all groups. The wound area was painless with no blister formation, but mild oedema was seen during the first three days.

The formation of a thick and dry crust was observed from day 3 onwards in all groups (Plate VII, Fig. 2A, 2E, 2I). Up to day 14, the wound crusts were demarcated on the burn region in the ABS and SSD groups, whereas it was not completely separated in the control group. After demarcation, the tissue underlying the crust was, in most cases, dark red or mottled and was considered as granulation tissue. In ABS and SSD groups, granulation tissue formation was easily noticeable at all wound edges and the wound size was reduced in both groups on day 14 (Plate VII, Fig. 2B, 2F, 2J). On day 21, all wounds continued to reduce in size in parallel to wound healing. The coverage of the wound base and wound filling with granulation tissue were remarkable in ABS and SSD groups. Control wounds had no evidence of elevation with granulation tissue (Plate VII, Fig. 2C, 2G, 2K). On day 28, all rats in the ABS and SSD groups had complete coverage of the wounds with granulation tissue and epithelialization, whereas wounds in the control group were not completely epithelialized (Plate VII, Fig. 2D, 2H, 2L). The wounds in all groups were clean and free of exudate throughout the study.

\section{Planimetry}

The mean unhealed wound areas and the mean percentages of wound contraction were not significantly different among the groups on day $7(P>0.05$, Table 1$)$. However, the mean unhealed wound area was larger and the mean percentage of wound contraction was lower $(P<0.05$, Table 1$)$ in the control group compared to the ABS and SSD groups on days 14,21 , and 28 . At the end of the study (day 28), the mean percentage of wound contraction in the ABS (100\%) and SSD (100\%) groups was better than in the control group $(P<0.05)$ (Table 1$)$. 


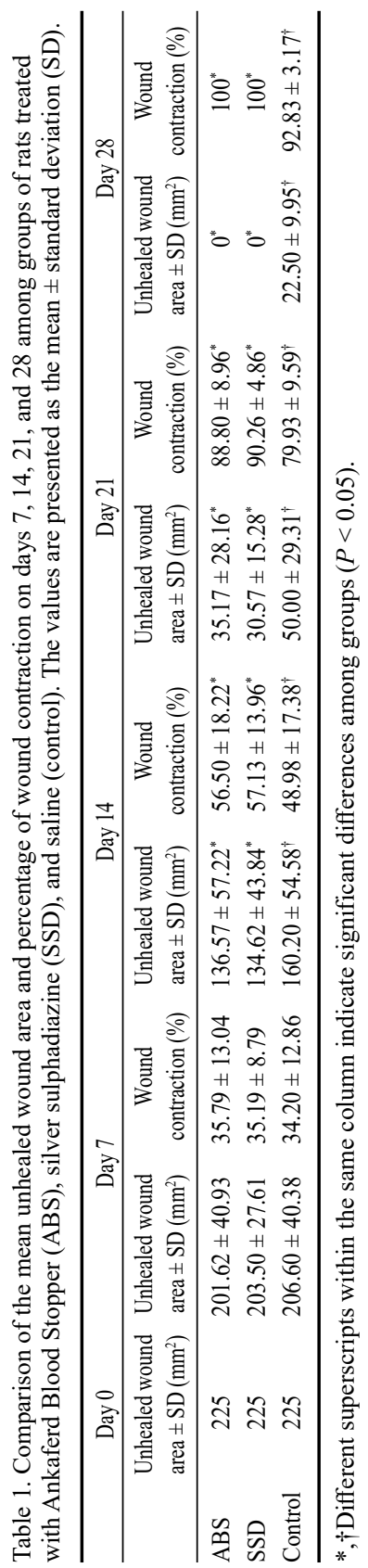

Histopathological examination

Results of the statistical analysis of neutrophil scores and vessel counts found during the study are presented in Table 2. Histopathological examination of the wounds revealed that ABS- and SSD-treated animals had significantly $(P=0.009)$ lower neutrophil scores than the control group. Vessel counts in these two groups were also higher than in the control group, although this could not be substantiated statistically. From day 7 to day 28 , a significant decrease in neutrophil scores and a significant increase in vessel counts (except on days 21 and 28) were observed (Plate VII, Fig. 3). When the treatment group and biopsy day were compared together, the neutrophil score was lower and the vessel count was higher in the ABS- and SSD-treated groups compared to the control group, although the difference was significant in very few instances.

\section{Discussion}

In this study we investigated for the first time the effects of a haemostatic agent, ABS, on deep second degree burn wound healing and compared its efficiency with SSD, an agent widely used for burn wounds. Skin burn wound is a common kind of cutaneous wound and its healing mechanism is very different from incisional or excisional wounds (Monstrey et al. 2008). The depth of the injury defines the healing process of the wound. The time required for complete healing of deep second degree burns, without the application of specific therapeutic agents, can be three to six weeks or more, and these burns will leave scar tissue that may hypertrophy or contract itself (Johnson and Richard 2003; Elsner et al. 2011).

In our study, a partial thickness contact burn injury was achieved by a circular brass disc of a $2 \mathrm{~cm}$ diameter that was heated to $88-90{ }^{\circ} \mathrm{C}$ for $20 \mathrm{~s}$ without exerting any external pressure as described by Lakshmi et al (2011). The depth of the burn wound was confirmed by histopathological examination.

Johnson and Richard (2003) described deep second degree burns to be of a pale colour with pain of lower intensity compared to superficial second degree burns. In the current study, hyperaemia varied from slight to absent in the first three days after wound creation. The formation of a thick and dry crust was observed from day 3 onwards. Signs of scar tissue formation were observed at the edge of the lesion from day 14 onwards.

Topical treatment is very important in the treatment of burns, and multiple methods or agents have been used, sometimes with conflicting results (Tavares Pereira Ddos et al. 2012a). The SSD was initially introduced in the 1960s and has been a mainstay of treatment for the care of burns since then. It is able to penetrate the eschar, accelerates the wound healing process through the inhibition of 
Table 2. Mean neutrophil and vessel counts of burn wounds in rats treated with Ankaferd Blood Stopper (ABS), $1 \%$ silver sulphadiazine (SSD) cream, or saline control for 28 days.

\begin{tabular}{lcl}
\hline Treatment group & Neutrophil count & Vessel count \\
\hline ABS & $1.62 \pm 0.66^{*}$ & $5.10 \pm 2.37$ \\
SSD & $1.69 \pm 0.74^{*}$ & $4.87 \pm 2.59$ \\
Control & $2.12 \pm 0.66^{\dagger}$ & $4.10 \pm 1.40$ \\
$P$ & 0.009 & 0.288 \\
\hline
\end{tabular}

Biopsy day ${ }^{\dagger \dagger}$

$\begin{array}{lll}\text { Day 7 } & 2.41 \pm 0.58^{*} & 2.33 \pm 0.70^{*} \\ \text { Day 14 } & 2.00 \pm 0.59^{\dagger} & 4.21 \pm 1.28^{\dagger} \\ \text { Day 21 } & 1.62 \pm 0.58^{\ddagger} & 6.08 \pm 1.59^{\ddagger} \\ \text { Day 28 } & 1.21 \pm 0.51^{\beta} & 6.16 \pm 2.26^{\ddagger} \\ P & 0.000 & 0.000\end{array}$

Treatment group and biopsy day

$\begin{array}{lll}\text { ABS-Day 7 } & 2.25 \pm 0.46 & 2.38 \pm 0.92 \\ \text { SSD-Day 7 } & 2.38 \pm 0.52 & 2.25 \pm 0.71 \\ \text { Control-Day 7 } & 2.63 \pm 0.74 & 2.50 \pm 0.53 \\ P & 0.516 & 0.781\end{array}$

\begin{tabular}{lll}
\hline ABS-Day 14 & $1.88 \pm 0.64$ & $4.38 \pm 1.50$ \\
SSD-Day 14 & $1.88 \pm 0.64$ & $4.38 \pm 1.50$ \\
Control-Day 14 & $2.25 \pm 0.46$ & $3.88 \pm 0.83$ \\
$P$ & 0.340 & 0.687 \\
\hline ABS-Day 21 & $1.25 \pm 0.46^{*}$ & $6.63 \pm 1.41$ \\
SSD-Day 21 & $1.63 \pm 0.52$ & $6.63 \pm 1.41$ \\
Control-Day 21 & $2.00 \pm 0.53^{\dagger}$ & $5.00 \pm 1.51$ \\
$P$ & 0.034 & 0.053 \\
\hline ABS-Day 28 & $1.13 \pm 0.35$ & $7.00 \pm 2.00^{*}$ \\
SSD-Day 28 & $0.88 \pm 0.35^{*}$ & $6.50 \pm 3.07^{*}$ \\
Control-Day 28 & $1.63 \pm 0.52^{\dagger}$ & $5.00 \pm 0.93^{\dagger}$ \\
$P$ & 0.010 & 0.045 \\
\hline
\end{tabular}

${ }_{*, \dagger, \downarrow, \beta}$ Different superscripts within the same column indicate significant difference $(P<0.05)$.

" Values are the mean \pm standard deviation (SD) of days $7,14,21$, and 28 in the same group.

\# Values are the mean \pm standard deviation (SD) of the three groups on the same day.

matrix metalloproteinases, and increases epithelialization (Warriner and Burrell 2005). However, some researchers claimed that SSD delays re-epithelialization in burn wounds (Khorasani et al. 2009).

During the treatment of partial thickness burns, loose and adherent dead tissues are removed and the surgeon decides whether the wound will require skin grafting for coverage or if it will reepithelialize (Sheridan et al. 1997; Klasen 2000). Some researchers stated that SSD delayed the separation of dead tissue in deep wounds (Khorasani et al. 2009). Until day 14, we observed that topical SSD and ABS treatments promoted eschar separation and provided an easy and fast debridement compared to the control group. 
Hypertrophic and atrophic scar formation can be seen in the treatment of SSD, especially in processes longer than three weeks (Sheridan et al. 1997; Klasen 2000). We did not observe hypertrophic or atrophic scar formation or exuberant granulation tissue either in the SSD-treated or in the other animals in our study.

Wound contraction, or the wound shrinking process, is an indicator used for assessing wound healing (Tavares Pereira Ddos et al. 2012a). Wound contraction depends on the type and extent of damage, the tissue's reparative abilities, and general tissue health (O'Leary et al. 2002). In our study, the lesion area decreased gradually with time in all groups. Although all wounds in the ABS and SSD groups were totally covered and epithelialized on day 28, there were still open wounds in the control group, indicating that ABS and SSD have a higher inducing effect on wound contraction than saline. There was no difference in the coverage with granulation tissue and reepithelialization in the burn bed between SSD and ABS groups.

Ours is the first study investigating the effect of ABS treatment on deep second degree burn wound healing. The positive effect of ABS on wound healing in our study is consistent with other studies (Akalin et al. 2014; Gul Satar et al. 2014) which reported that ABS may be used effectively and safely on full-thickness wounds as a natural product. Healing of wounds treated with ABS has been shown to be superior to the control wounds in terms of inflammatory scoring, type I/type III collagen ratio, and wound contraction rates (Akalin et al. 2014). Application of ABS accelerates the filling of the open wound with granulation tissue to skin level and shortens the average healing time (Gul Satar et al. 2014).

Burns are prone to infection because of low immune response and the presence of large local debris which promotes an optimal environment for microorganisms. In the presence of infection, healing becomes very slow or does not take place at all (Church et al. 2006). During our study period, none of the wounds showed signs of infection. This may be due to the proven antimicrobial effects of ABS (Saribas et al. 2010) and SSD (Vloemans et al. 2003).

We did not observe any abnormal findings in the complete blood count throughout the study, which suggests that the topical applications of ABS or SSD do not result in systemic abnormalities indicated by this test. Overall, all rats were clinically healthy throughout the study.

For histopathological evaluation of wound healing, neutrophil scores (as an indication of inflammatory response) and vessel counts were selected as reported in some other studies (Cangul et al. 2006; Gul et al. 2008). A progressive decrease in neutrophil counts and a progressive increase in neovascularisation provide a useful guide for healing. In the current study, the beneficial effects of ABS and SSD were supported by lower neutrophil scores and higher vessel counts in animals treated with these agents.

In conclusion, we observed that $\mathrm{ABS}$, marketed as a haemostatic agent, has beneficial effects on burn wound healing in rats comparable to those of the widely used SSD. Daily topical applications of ABS accelerated granulation, reepithelialization, and wound retraction. These results suggest that ABS may provide a good alternative for the treatment of burn wounds in rats. Its efficiency in other species needs to be further studied.

\section{References}

Akalin C, Kuru S, Barlas AM, Kismet K, Kaptanoglu B, Demir A, Astarci HM, Ustun H, Ertas E 2014: Beneficial effects of Ankaferd Blood Stopper on dermal wound healing: An experimental study. Int Wound J 11: 64-68

Akbal E, Köklü S, Karaca G, Astarcı HM, Koçak E, Taş A, Beyazıt Y, Topcu G, Haznedaroğlu IC 2012: Beneficial effects of Ankaferd Blood Stopper on caustic esophageal injuries: An experimental model. Dis Esophagus 25: 188-194

Arslan K, Karahan O, Okuş A, Unlü Y, Eryılmaz MA, Ay S, Sevinç B 2012: Comparison of topical zinc oxide and silver sulfadiazine in burn wounds: An experimental study. Ulus Travma Acil Cerrahi Derg 18: 376-383

Cangul IT, Gul NY, Topal A, Yilmaz R 2006: Evaluation of the effects of topical tripeptide-copper complex and zinc oxide on open-wound healing in rabbits. Vet Dermatol 17: 417-423 
Church D, Elsayed S, Reid O, Winston B, Lindsay R 2006: Burn wound infections. Clin Microbiol Rev 19: 403-404

Elsner JJ, Egozi D, Ullmann Y, Berdicevsky I, Shefy-Peleg A, Zilberman M 2011: Novel biodegradable composite wound dressings with controlled release of antibiotics: results in a guinea pig burn model. Burns 37: 896-904

Fuller FW 2009: The side effects of silver sulfadiazine. J Burn Care Res 30: 464-470

Gul NY, Topal A, Cangul IT, Yanik K 2008: The effects of topical tripeptide copper complex and helium-neon laser on wound healing in rabbits. Vet Dermatol 19: 7-14

Gul Satar NY, Cangul IT, Topal A, Oktay MA, Inan K, Akgul MB 2014: Effects of Ankaferd Blood Stopper (ABS) and topical tripeptide copper complex (TCC) on wound healing in rats: an experimental study. Kafkas Univ Vet Fak Derg 20: 545-551

Gupta SS, Singh O, Bhagel PS, Moses S, Shukla S, Mathur RK 2011: Honey dressing versus silver sulfadiazine dressing for wound healing in burn patients: a retrospective study. J Cutan Aesthet Surg 4: 183-187

Johnson RM, Richard R 2003: Partial-thickness burns: identification and management. Adv Skin Wound Care 16: $178-187$

Juhász I, Zoltán P, Erdei I 2012: Treatment of partial thickness burns with Zn-hyaluronan: lessons of a clinical pilot study. Ann Burns Fire Disasters 25: 82-85

Khorasani G, Hosseinimehr SJ, Azadbakht M, Zamani A, Mahdavi MR 2009: Aloe versus silver sulfadiazine creams for second-degree burns: A randomized controlled study. Surg Today 39: 587-591

Klasen HJ 2000: A historical review of the use of silver in the treatment of burns. II. Renewed interest for silver. Burns 26: 131-138

Kumar MS, Sripriya R, Raghavan HV, Sehgal PK 2006: Wound healing potential of Cassia fistula on infected albino rat model. J Surg Res 131:283-289

Lakshmi TS, Shanmugasundaram N, Shanmuganathan S, Babu M 2011: Efficacy of desulfated heparin mitigating inflammation in rat burn wound model. J Biomed Mater Res B Appl Biomater 97: 215-223

Monstrey S, Hoeksema H, Verbelen J, Pirayesh A, Blondeel P 2008: Assessment of burn depth and burn wound healing potential. Burns 34: 761-769

O’Leary R, Wood EJ, Guillou PJ 2002: Pathological scarring: strategic interventions. Eur J Surg 168: 523-534

Saribas Z, Sener B, Haznedaroglu IC, Hascelik G, Kirazli S, Goker H 2010: Antimicrobial activity of Ankaferd Blood Stopper ${ }^{\circledR}$ against nosocomial bacterial pathogens. Cent Eur J Med 5: 198-202

Sheridan RL, Petras L, Lydon M, Salvo PM 1997: Once-daily wound cleansing and dressing change: efficacy and cost. J Burn Care Rehabil 18: 139-140

Tavares Pereira Ddos S, Lima-Ribeiro MH, de Pontes-Filho NT, Carneiro-Leão AM, Correia MT 2012a: Development of animal model for studying deep second-degree thermal burns. J Biomed Biotechnol 2012a: 460841

Tavares Pereira Ddos S, Lima-Ribeiro MH, Santos-Oliveira R, Cavalcanti Cde L, de Pontes-Filho NT, Coelho LC, Carneiro-Leão AM, Correia MT 2012b: Topical application effect of the Isolectin hydrogel $($ Cramoll 1,4) on second-degree burns. Experimental model. J Biomed Biotechnol 2012b: 184538

Vloemans AF, Soesman AM, Suijker M, Kreis RW, Middelkoop E 2003: A randomised clinical trial comparing a hydrocolloid-derived dressing and glycerol preserved allograft skin in the management of partial thickness burns. Burns 29: 702-710

Warriner R, Burrell R 2005: Infection and the chronic wound: A focus on silver. Adv Skin Wound Care 18 (Suppl. 1): 2-12 
Plate VI

Topal A. et al.: Ankaferd blood ... pp. 261-267

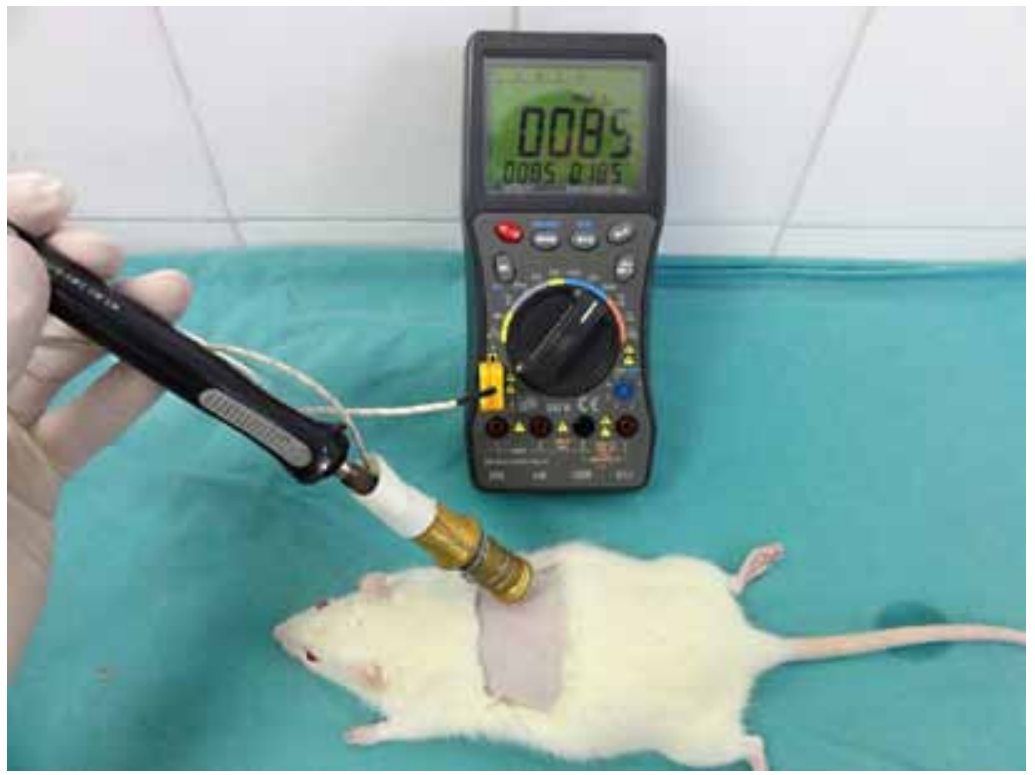

Fig. 1a. The instrument used for creating burn wounds. The circular brass disc was stabilized at $88-90{ }^{\circ} \mathrm{C}$ and contacted to the shaved dorsal skin of rats for $20 \mathrm{~s}$ without exerting any external pressure.

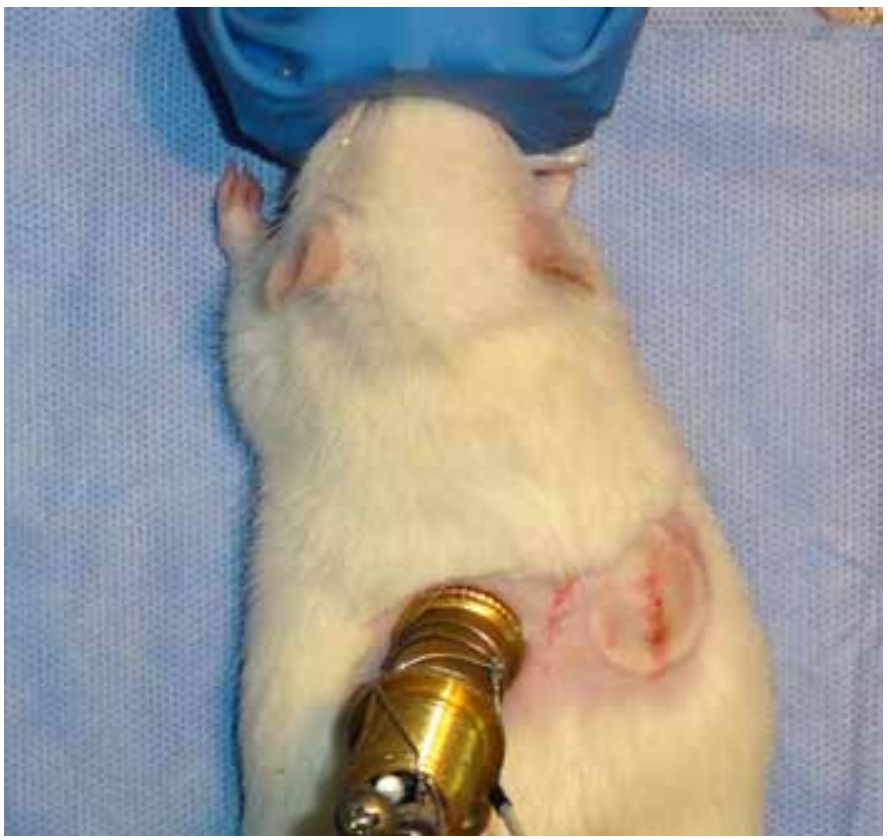

Fig. 1b. The depth of the burn wound 

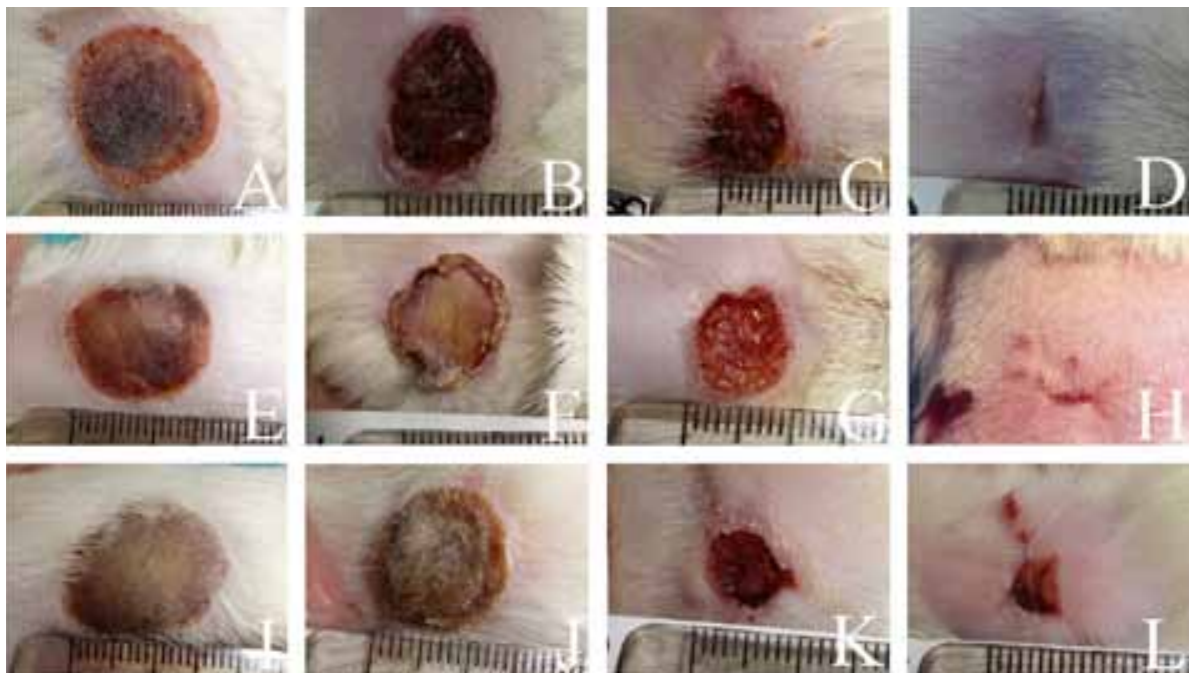

Fig. 2. The figure shows the progression of burn wound healing in the ABS (1A to $1 \mathrm{D})$, SSD (1E to $1 \mathrm{H})$ and control (1I to $1 \mathrm{~L}$ ) groups on day 7 (first column), day 14 (second column), day 21 (third column), and day 28 (fourth column). On day 28, all rats in the ABS and SSD groups had a complete coverage of the wounds with granulation tissue and epithelialization, whereas wounds in the control group were still open.
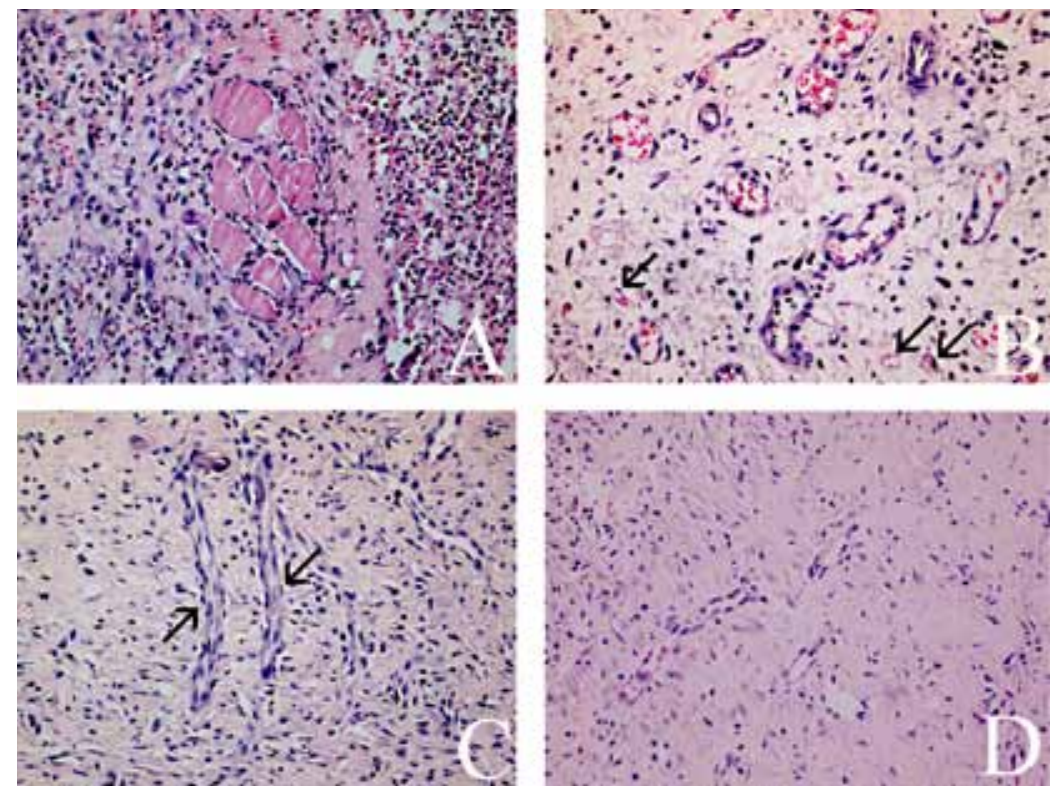

Fig. 3. Histopathologically, burn wound healing was characterized by a decrease in the neutrophil count and an increase in the vessel count (Photographs of the ABS group). Figure 3A shows the high neutrophil count on day 7. Figure 3B shows new capillaries (arrows) in addition to the preexisting ones on day 14. Newly formed capillaries (arrows) were in most instances perpendicular to the wound surface on day 21 (Fig. 3C). Neutrophil counts were markedly decreased on day 28 (Fig. 3D). H\&E staining, $\times 400$ magnification. 